\section{Estudo \\ cobebate}

em Testão

Plamejamento
Revista Estudo \& Debate, Lajeado, v. 24, n. 3, 2017. ISSN 1983-036X

DOI: http://dx.doi.org/10.22410/issn.1983-036X.v24i3a2017.1373

\title{
UMA ANÁLISE DO EFEITO DA LEI MARIA DA PENHA NO RIO GRANDE DO SUL
}

\author{
Eduarda Miller de Figueiredo ${ }^{1}$, Daniel de Abreu Pereira Uhr², Júlia Gallego Ziero Uhr ${ }^{3}$
}

Resumo: O objetivo deste artigo é analisar a efetividade da Lei Maria da Penha no Estado do Rio Grande do Sul. Utiliza-se o método de dados em painel para verificar o efeito da Lei Maria da Penha para o Rio Grande do Sul. Em termos mais específicos, utiliza-se o método de diferenças em diferenças generalizadas (Generalized difference-in-difference model - GDD) permite verificar o impacto da legislação comparando as diferenças entre as médias antes e depois da mudança legislativa entre os grupos considerados. Os dados são do Serviço de Informaçôes Policiais/Companhia de Processamento de Dados do Estado do Rio Grande do Sul (SIP/PROCERGS), do Departamento de Informática do SUS (DATASUS) e do Instituto Brasileiro de Geografia e Estatística (IBGE), para o período de 2002 a 2009. Considera-se o número de homicídios como medida de violência. Os resultados empíricos mostram que a lei foi efetiva no combate a violência feminina reduzindo, assim, o número de homicídios em comparação com o grupo dos homens.

Palavras-chave: Análise de efetividade de lei. Lei Maria da Penha. Diferenças em Diferenças.

\begin{abstract}
The purpose of this article is to analyze the effectiveness of the Maria da Penha Law in the State of Rio Grande do Sul. The panel data method is used to verify the effect of the Maria da Penha Law for Rio Grande do Sul. The Generalized difference-in-difference model (GDD) is used to verify the impact of legislation comparing the differences between the averages before and after the legislative change between the groups considered. The data are from the Police Information Service / Data Processing Company of the State of Rio Grande do Sul (SIP / PROCERGS), the Department of Information Technology of SUS (DATASUS) and the Brazilian Institute of Geography and Statistics (IBGE), from 2002 to 2009. The number of homicides is considered as a measure of violence. The empirical results show that the law was effective in combating female violence, thus reducing the number of homicides compared to men.
\end{abstract}

Keywords: Law effectiveness analysis, Maria da Penha Law, Differences in Difference Model.

1 Bacharel em Ciências Econômicas pela Universidade Federal de Pelotas (UFPel), e bacharel em Direito pela Universidade Católica de Pelotas (UCPel). E-mail: eduardamillerdefigueiredo@gmail.com

2 Doutor em Economia pela Universidade de Brasília (UnB). Pós-doutor pela University of Alberta; PósDoutor pela Universidade de São Paulo (USP). Professor permanente do Programa de Pós-Graduação em Organizações e Mercados (PPGOM/UFPel). Professor adjunto do Departamento de Economia da UFPel (UFPel). E-mail:daniel.uhr@gmail.com

3 Doutora em Economia pela Universidade de Brasília (UnB). Pós-doutora pela University of Alberta ; PósDoutora pela Universidade de São Paulo (USP). Professora permanente do Programa de Pós-Graduaçáo em Organizaçóes e Mercados (PPGOM/UFPel). Professor a adjunta do Departamento de Economia da UFPel (UFPel).E-mail:zierouhr@gmail.com 


\section{Introdução}

A violência contra a mulher é um dos grandes problemas a ser superado por toda a sociedade mundial, já que, na última década houve 43,7 mil homicídios femininos somente no Brasil. Em consequência disso, o país está ocupando o $7^{\circ}$ lugar no ranking mundial, onde uma porcentagem bastante significativa dessas mortes ocorreu dentro da própria residência da vítima, sendo o parceiro ou o ex-parceiro da vítima o agressor (WAISELFISZ, 2012, p. 8 e 16).

A ONU vem procurando combater a agressão contra a mulher desde 1975, ano da $1^{\circ}$ Conferência Mundial sobre a Mulher na cidade do México, definindo-a como uma violência aos direitos humanos, e como consequência passou a pressionar para que fosse criada uma política que combata esse tipo de crime.

Em consequência do Relatório no 54/2001 publicado pela Comissão Interamericana de Direitos Humanos da OEA, onde se afirmou que o Brasil não cumpriu o compromisso do combate à violência doméstica ao demorar em prender o agressor do caso Maria da Penha, foi criada a Lei no $11.340 / 06$ para reverter o quadro crítico da violência contra a mulher, procurando uma forma de proteger as mulheres dos agressores, que na maioria das vezes são os próprios companheiros com quais escolheram se relacionar ou daqueles que deveriam ser os responsáveis em zelar por sua segurança, educação e saúde. A lei é destinada a mulheres em situação de vulnerabilidade, onde sua integridade física, moral e psicológica está em constante ameaça, desejando reduzir a sensação de insegurança e medo da mulher.

A ciência econômica através de seus métodos de pesquisas nos dá condiçóes de concluir se houve ou não um real impacto na redução dos homicídios femininos motivados pela violência de gênero, um estudo de grande importância para enfrentar a violência que vitimiza diversas mulheres no Brasil e no mundo.

Este estudo acerca da efetividade da Lei Maria da Penha no Estado do Rio Grande do Sul utilizará o método de diferenças em diferenças generalizadas (Generalized difference-indifference model in panel data - GDD) com dados dos homicídios masculinos como grupo de controle, e os dados de homicídios femininos como grupo de tratamento, para os anos de 2002 a 2009 em todos os municípios do Rio Grande do Sul. Estes dados foram retirados de fontes como DATASUS ${ }^{4}$, IBGE $^{5}$ e SIP/PROCERGS ${ }^{6}$. Além disso, utiliza-se variáveis de controle como registros de casamentos, divórcios e separaçóes judiciais, a densidade populacional, posse de entorpecentes, entre outros.

O presente artigo foi organizado em seis seções. Além desta introdução, na segunda seção foi discutida a Lei Maria da Penha, através de uma breve análise de seus principais artigos e do histórico da violência contra a mulher, a literatura empírica existente no Brasil e em outros países referentes ao tema proposto neste trabalho. $\mathrm{Na}$ terceira seção,

4 Maiores informações no site: http://datasus.saude.gov.br/

5 Instituto Brasileiro de Geografia e Estatística, http://www.ibge.gov.br/home/

6 http://www.procergs.rs.gov.br/inicial 
apresentam-se os dados utilizados e o método a ser empregado para calcular a efetividade da LMP. A quarta seção apresenta-se os resultados obtidos, e na última seção, apresenta-se as considerações finais.

\section{Referencial Teórico}

Esta seção está dividida em duas subseçôes. A primeira apresenta as disposições legais sobre a violência contra a mulher, o histórico e uma breve descrição da Lei ${ }^{\circ} 11.340 / 06$. A segunda subseção o referencial empírico, tanto nacional quanto internacional.

\subsection{Disposiçôes legais sobre a violência contra a mulher}

\subsubsection{Histórico}

Foi proclamada pelas Organizações das Naçóes Unidas na $1^{\circ}$ Conferência Mundial sobre a Mulher na Cidade do México, que a partir daquele ano, 1975 até 1985, seria a Década das Naçóes Unidas para a Mulher. Como consequência dessa conferência, nasceu na Assembleia Geral da ONU no dia 18 de dezembro de 1979, a Convenção da Mulher, entretanto só em 1993 que a ONU, na Conferência de Direitos Humanos, definiu a violência contra a mulher como uma violação dos direitos humanos.

A Assembleia Geral da Organização dos Estados Americanos (OEA) adotou em 1994 a Convenção Interamericana para Prevenir, Punir e Erradicar a Violência Doméstica ou também chamada por Convenção de Belém do Pará que passou a considerar a violência contra a mulher como um problema de saúde pública. Essa ideia foi incorporada ao ordenamento jurídico brasileiro em 1995, entrando em vigor em agosto de 1996, conceituando a violência contra a mulher como "qualquer ato ou conduta baseada no gênero, que cause morte, dano ou sofrimento físico, sexual ou psicológico à mulher, tanto na esfera pública como na esfera privada" (BRASIL, Decreto n¹.973/96).

O Brasil só passou a atender à recomendação da OEA após a publicação do Relatório no 54/2001 da Comissão Interamericana de Direitos Humanos onde afirma que o Brasil apresentou ineficácia judicial ao demorar em julgar e prender o agressor de Maria da Penha, demonstrando falta de compromisso, por ele assumido, de reagir perante a violência doméstica. Sendo assim, criou a Lei no 11.340/06, conhecida pelo nome da vítima.

A vítima em questão era Maria da Penha Maia Fernandes que, em 29 de maio de 1983, na cidade de Fortaleza, foi vítima de um disparo feito pelo seu marido enquanto dormia, deixando-a paraplégica. Uma semana depois, enquanto tomava banho, ela recebeu uma descarga elétrica, também pelo seu marido, que foi denunciado em 28 de setembro de 1984 e preso somente em setembro de 2002.

Em março de 2015, foi alterado o dispositivo do artigo 121 do Código Penal, que passa a prever o feminicídio como uma qualificadora do crime de homicídio. Além disso, o feminicídio passa a ser considerado, através da Lei $\mathrm{n}^{\circ}$ 8.072/90, como um crime hediondo onde a pena deverá ser cumprida integralmente em regime fechado, não permitido, então, 
a progressão, também em consequência da hediondez do crime cometido pelo agressor, ele será transferido para um estabelecimento penal de segurança máxima.

\subsubsection{Lei Maria da Penha (LMP) - 11.340/06}

A Lei ${ }^{\circ} 11.340 / 06$ foi criada para coibir e prevenir a violência doméstica e familiar contra a mulher. Nos artigos $2^{\circ}$ e $3^{\circ}$ apresentam direitos e garantias fundamentais que seriam próprios a todo e qualquer ser humano, tanto do sexo masculino como do feminino, uma vez que a Constituição Federal no seu artigo $5^{\circ}$ já apresenta tais determinaçóes. Porém, ao lembrarmo-nos da história da construção dos direitos humanos, percebe-se que no início era ocorrida a exclusão da mulher como sujeito de direito, por isso, a importância da explicitação de todos os direitos e garantias fundamentais à mulher.

A lei é destinada à situação de vulnerabilidade no seio de uma relação doméstica, familiar ou de afeto, portanto, para sua interpretação é necessário observar se o caso de violência está encaixado nas características de indefensibilidade descritas.

Todas as situações elencadas no artigo $5^{\circ}$ da LMP determinam quais são as formas desse ilícito, seja numa unidade doméstica, numa relação familiar ou numa relação íntima de afeto, e sequer há necessidade de vínculo entre agressor e vítima. É configurado como violência doméstica e familiar contra a mulher qualquer ação ou omissão baseada no gênero, e onde, o artigo $7^{\circ}$, determina quais são as formas desse ilícito:

I - a violência física, entendida como qualquer conduta que ofenda sua integridade ou saúde corporal;

II - a violência psicológica, entendida como qualquer conduta que lhe cause dano emocional ou diminuiçấo da autoestima ou que lhe prejudique e perturbe o pleno desenvolvimento ou que vise degradar ou controlar suas açóes [...];

III - a violência sexual, entendida como qualquer conduta que a constranja a presenciar, a manter ou a participar de relação sexual não desejada [...] que a impeça de usar qualquer método contraceptivo ou que a force ao matrimônio, à gravidez, ao aborto ou à prostituição, mediante coação, chantagem, suborno ou manipulação, ou que limite ou anule o exercício de seus direitos sexuais e reprodutivos;

IV - a violência patrimonial, entendida como qualquer conduta que configure retenção, subtração, destruição parcial ou total de seus objetos, instrumentos de trabalho, documentos pessoais, bens, valores e direitos ou recursos econômicos [...];

$\mathrm{V}$ - a violência moral, entendida como qualquer conduta que configure calúnia, difamação ou injúria.

Em toda a violência baseada no gênero, deve ficar evidente a vontade e a consciência do agente de atingir a mulher em vulnerabilidade, o que apenas seria possível nos crimes dolosos, já que os crimes culposos são uma inobservância do dever de cuidar.

$\mathrm{O}$ parágrafo único do artigo $5^{\circ}$ determina que a violência independa de orientação sexual, podendo o agressor ser um homem (união heterossexual) ou outra mulher (união homoafetiva). Para Lima (2014, p. 886 e 887), no caso de uma violência dentro de uma relação doméstica, familiar ou íntima de afeto, onde o sujeito ativo e o passivo são mulheres, há uma presunção relativa da situação de vulnerabilidade da "mulher-vítima" e com isso 
não há nenhum critério para justificar a aplicação da Lei Maria da Penha. No entanto, também afirma que caso a violência ocorra dentro de uma uniâo homoafetiva e que fique claro a posição de superioridade da agressora em relação à vítima, será possível a aplicação da Lei $n^{\circ} 11.340 / 06$, visto que foi sinalizada a situação de vulnerabilidade da vítima. Esse é o mesmo pensamento da lição dada por Dias (2013, p.10), que afirma que se deve levar em consideração que a Lei Maria da Penha alcança as relaçóes homoafetivas quando fala que está assegurada a proteção da mulher independentemente da orientação sexual, desde que mantenham relação íntima de afeto.

Para ser considerada uma violência no âmbito da unidade doméstica é indispensável que o agressor e a vítima façam parte dessa mesma unidade doméstica, ou seja, espaço de convívio permanente de pessoas. Enquanto no âmbito familiar, a infração penal deverá ser praticada entre pessoas unidas por vínculo jurídico de natureza familiar, podendo ser conjugal, parentesco (linha reta ou afinidade) ou por vontade expressa, como no caso de adoção. Já numa relação íntima de afeto, o artigo $5^{\circ}$ inciso III da Lei Maria da Penha dispensa o requisito da coabitaçáo, ultrapassando a norma internacional que serviu de inspiração para essa Lei, a Convenção de Belém de Pará, que abrange apenas as relaçóes em que haja coabitação entre o agressor e a vítima. Por essa razão, Nucci (2010, p. 1264) apoia que a Lei Maria da Penha não seja aplicada em uma relação íntima em que não haja coabitação, enquanto Dias (2012) acredita que é possível a aplicação dessa norma por conta do princípio que determina que a norma mais favorável para a vítima é a que deve prevalecer, sendo assim, aquela que dispensa a coabitação.

Em relação à assistência à mulher em situação de violência doméstica e familiar, a Lei Maria da Penha determina que o juiz inclua a vítima, por tempo determinado, em programas assistenciais do governo, além de permitir a manutenção do vínculo trabalhista, já que em determinadas situaçóes desse tipo de violência, é necessário o afastamento do local de trabalho num período de até seis meses. É criado pelo artigo 14 um órgão especializado com competência para o processo, julgamento e execução das penas para os casos violência doméstica e familiar, o chamado Juizado de Violência Doméstica e Familiar contra a Mulher que funciona através da Justiça Estadual, ademais determina que no horário noturno possam ser realizados os atos processuais.

Os artigos 16 e 41 da Lei Maria da Penha possuem uma contradição entre eles, já que a Lei $n^{\circ}$ 9.099/95, que dispóe sobre os Juizados Especiais Cíveis e Criminais, determina que os crimes de lesão corporal leve e de lesão corporal culposa dependam de representação, contudo, caso esses delitos sejam praticados no contexto da Lei $n^{\circ} 11.340 / 06$, há uma polêmica doutrinária entre ser necessária a representação ou não. De um lado está o artigo 16, no qual se entende que é exigível a representação, do outro há o artigo 41, determinando que a Lei n ${ }^{\circ}$ 9.099/95 não será aplicada nos casos de violência doméstica e familiar contra a mulher. Essa desarmonia foi levada até o Superior Tribunal de Justiça que com base nos dados estatísticos que revelam que na maioria dos casos de agressão leve a ofendida não representa por vício da vontade dela, conclui que a Lei no 9.099/95 não será aplicada no âmbito da Lei Maria da Penha, visto que, deixar a representação na mão da vítima é uma 
contribuição para a prorrogação do quadro de violência, já que a violência tende a se tornar mais grave ${ }^{7}$.

Em relação às medidas protetivas, que são, por exemplo, o afastamento do lar ou a proibição de aproximaçáo da ofendida, presente nos artigos 19 e 22, é determinado que fossem concedidas por um juiz para mulheres, crianças, adolescentes, enfermos, idosos ou pessoas com deficiência, quando constatada a violência. Após requerimento da própria ofendida ou do Ministério Público, serão concedidas de imediato, observado os pressupostos. Elas poderão ser substituídas em qualquer momento por outro tipo de medida preventiva de maior eficácia, podendo ser aplicadas de forma conjunta ou separadamente. A LMP também permite a prisão preventiva do agressor em qualquer fase do inquérito policial ou instrução criminal, desde que o juiz de ofício decrete.

\subsection{Literatura Empírica}

Recentemente vem surgindo uma nova área de pesquisa onde se avalia o impacto de determinadas leis na sociedade, nos quais autores analisam a efetividade da lei. Como, por exemplo, no artigo publicado por Shimada, Kannebley Jr. e Negri (2013), que avaliam o impacto dos incentivos públicos à pesquisa e desenvolvimento através de estimaçóes de modelos empíricos com dados em painel. Furtado e Silva Filho (2014) também realizaram um estudo nesse campo quando investigaram a restrição ao fumo em ambientes de uso coletivo e sua efetividade nas internações hospitalares, através dos métodos de seleção em observáveis e de diferenças em diferenças.

$\mathrm{Na}$ área da Lei Maria da Penha, ainda são escassos os estudos empíricos de avaliação da efetividade desse marco importante para o Brasil e para o mundo. Mesmo que tenha sido sancionada há oito anos, só há dois trabalhos publicados sobre o impacto da lei na sociedade, o que demonstra uma grande falta para a resolução do complexo problema da violência fatal contra o gênero feminino.

O primeiro estudo nessa vertente foi realizado por Garcia, Freitas e Höfelman (2013), que, através de estudo de séries temporais constatou que não houve redução das taxas anuais de mortalidade, apenas percebendo um suave decréscimo logo após a vigência da LMP, mas que logo após retornou aos valores anteriores. Porém, como as autoras não observaram as abordagens quantitativas, pode-se dizer que é uma avaliação superficial do impacto da lei. Cerqueira et al. (2015) buscando suprir a lacuna acerca da efetividade da Lei n 11.340/06, realiza através do modelo de diferenças em diferenças uma avaliação do efeito desta lei em âmbito nacional, confrontando os homicídios contra mulheres que ocorreram em suas residências contra aqueles que vitimaram pessoas do sexo masculino.

Através da estimação de painel espacial dos estados brasileiros entre 2005 e 2009 , Uchôa e Menezes (2012) procuram mostrar quais são as condicionantes da violência no Brasil. Foi concluído pelo modelo de efeitos fixos que um aumento na impunidade leva

7 STF, Pleno, ADI 4.424/DF, Rel. Min. Marco Aurélio, j. 09/02/2012. A partir da decisão proferida pelo STF na ADI 4.424, o Superior Tribunal de Justiça se viu obrigado a alterar seu entendimento: STJ, $6^{\circ}$ Turma, HC 145.577, Rel. Min. Assussete Magalhães, j. 18/09/2012, DJe 11/10/2012. 
a um aumento nos homicídios, além disso, demonstra que estados que mais investem na segurança são também os mais violentos, contrariando o argumento de que mais investimento em segurança pública diminuiria o nível de criminalidade. Eles explicam esse resultado com base no tipo de política que o Brasil adota para resolver seus problemas, já que os investimentos só acontecem após a situação tornar-se crítica, demandando grande volume de recursos.

A atualização do Mapa da Violência, realizado por Waiselfisz (2012), foi focado no homicídio contra as mulheres no Brasil, já que este é o material utilizado para estudos de diversas instituiçóes que procuram mobilizar a sociedade e encadear políticas de enfrentamento da violência contra a mulher, fornecendo então, um panorama mais recente da situação. Utilizou como fontes o Sistema de Informaçóes de Mortalidade (SIM), a Secretaria de Vigilância em Saúde (SVS), o Ministério da Saúde (MS), a Organização Mundial da Saúde (OMS), Censos Demográficos do IBGE, entre outros, com dados referentes ao ano de 2010. Ao final da pesquisa encontram que, 43,7 mil mulheres foram mortas apenas na última década, no qual a Lei $\mathrm{n}^{\circ} 11.340 / 06$ trouxe um pequeno decréscimo no seu primeiro ano de vigência, completado em 2007, mas que até 2010 voltou a crescer de forma rápida. O Rio Grande do Sul ocupa a $19^{\circ}$ posição com uma taxa de 4,1 homicídios em 100 mulheres e o Brasil se encontra como $7^{\circ}$ país com maior taxa de homicídios femininos. As maiores taxas de vitimização estão situadas na faixa dos 15 aos 29 anos de idade, nos quais o agressor é o parceiro ou o ex-parceiro da vítima e que a maioria das agressóes se sucedem dentro das residências, onde $44,2 \%$ das agressões são físicas. Foi concluído que os níveis altos de feminicídio estão acompanhados de níveis altos de tolerância da violência contra as mulheres, através da prática em culpar a vítima por causa da violência de gênero, em que a própria existência de Leis especiais, como a Maria da Penha, indica a vulnerabilidade do setor.

Schraiber et al. (2002) procuram identificar a natureza da violência contra a mulher, a sua gravidade e a relação agressor x vítima, através de uma pesquisa padronizada, aplicada entre usuárias de uma unidade básica de saúde durante dois meses de 1998, em São Paulo, com idade entre 15 e 49 anos. A pesquisa só utilizou a palavra "violência” no final da entrevista, para entender o que a vítima considerava como violência, evidenciando que $45 \%$ das mulheres não consideram a ofensiva como um ato violento, provavelmente porque elas não nomeiam a situação doméstica como violência, conclui os autores. Assim, 143 mulheres, de um total de 322, relataram que tinham sofrido no mínimo um episódio de violência física, e 37 informaram pelo menos uma violência sexual, sendo que 110 casos, a agressão partiu do companheiro ou de familiares. Logo, foi concluído que esse tipo de violência ocorre principalmente por companheiros ou familiares e que, na maioria dos casos, as agressóes são severas e repetitivas.

Ao analisar os fatores desencadeantes para a violência contra a mulher, através uma abordagem quantitativa na delegacia da mulher de João Pessoa, com uma população de 50 processos, de fevereiro e março de 2010 e 2011, meses em que ocorreram um maior número de registros de agressão, Silva et al. (2013), mostra que a maioria das vítimas da violência doméstica e familiar possuem idade entre 21 e 25 anos (26\%), com união estável (48\%), com ensino fundamental completo (33\%) e donas do lar (37\%). As agressóes, em sua maioria, 
ocorreram nas suas próprias residências (87\%), nos quais o abuso de álcool e o ciúme são fatores que levam à violência, já que os agressores, em geral, são seus companheiros (70\%).

Cerqueira et al. (2015) procurando completar os estudos empíricos para avaliar o efeito da Lei Maria da Penha construiu um modelo econométrico com base no método de diferenças em diferenças, onde indica que a lei impôs um papel importante para conter a violência contra a mulher, todavia não teve uma efetividade de maneira uniforme no país, visto que a Lei incentiva a criação de Delegacias de Mulheres, juizados especiais, casas de abrigo etc..., e locais que não se mobilizaram para implementar esses serviços, dificilmente obtiveram alguma alteração na crença de seus moradores, no sentido do aumento da probabilidade de sançóes. Foram acessados os dados do SIM e do Ministério da Saúde, com uma análise de agressôes letais, utilizando apenas aqueles homicídios ocorridos nas residências, já que $90 \%$ das mortes por violência de gênero ocorrem por companheiros ou ex-companheiros (CERQUEIRA et al., 2015). Concluiu entáo, que apesar de aumentar o custo da pena para o agressor e de aumentar a probabilidade de condenação, a sua eficácia no país se deu de forma desuniforme, pois a utilidade da lei depende de institucionalização de diversos serviços protetivos.

\section{Metodologia}

\subsection{Dados}

Os dados utilizados para realizar esse presente estudo, foram retirados do Sistema de Informaçóes Policiais e Companhia de Processamento de Dados do Estado do Rio Grande do Sul (SIP/PROCERGS), do Departamento de Informática do SUS (DATASUS) e do Instituto Brasileiro de Geografia e Estatística (IBGE), para os anos de 2002 a 2009.

Foram considerados todos os municípios do Estado do Rio Grande do Sul, num total de 497 cidades, do ano de 2002 a 2009. Os dados dessa análise referem-se ao número de homicídios por gênero, masculino e feminino, renda, posse de entorpecentes, existência ou não de delegacias de mulheres, número de casamentos, de divórcios e de separações judiciais8. Também, considera-se a variável Lei Maria da Penha, a qual é uma variável binária, que assume valor 0 para os anos anteriores à publicaçấo da Lei, de 2002 a 2005, e o valor 1 para os anos posteriores à Lei, isto é, 2006 a 2009.

8 Separaçôes e divórcios foram computadas conjuntamente, devido ao seu efeito prático de fim da uniáo matrimonial. 
Tabela 1 - Estatísticas Descritivas para dados pooled

\begin{tabular}{l|l|c|c|c|c}
\hline \multicolumn{1}{c|}{ Variável } & \multicolumn{1}{|c|}{ Descriçáo } & Média & D.P. & Mín. & Máx. \\
\hline Homicídios & $\begin{array}{l}\text { Número de homicídios } \\
\text { cometidos contra pessoas dos } \\
\text { sexos masculino e feminino }\end{array}$ & 2,0764 & 18,5271 & 0 & 636 \\
\hline Delegacias & $\begin{array}{l}\text { Número de Delegacia de } \\
\text { Mulher nos municípios após } \\
\text { a publicaçáo da LMP }\end{array}$ & 0,0055 & 0,0742 & 0 & 1 \\
\hline Densidade & Densidade populacional & 84,5713 & 309,5789 & 1,6322 & 2940,836 \\
\hline Renda & Renda per capita & 317763,9 & 1541173 & 7561 & $3,69 \mathrm{e}+07$ \\
\hline Casamentos & Número de casamentos & 71,2314 & 247,2189 & 0 & 5001 \\
\hline Separdivor & $\begin{array}{l}\text { Número de separaçóes e de } \\
\text { divórcios }\end{array}$ & 30,1358 & 119,16 & 0 & 2679 \\
\hline Pentorpe & Posse de entorpecentes & 13,6666 & 105,3693 & 0 & 2646 \\
\hline
\end{tabular}

Fonte: SIP/PROCERGS, DATASUS e IBGE 2002 a 2009.

Foram, portanto, utilizadas ao todo oito variáveis de controle, visto que seja necessário controlar o ambiente de relação familiar e doméstica que ocorre em casos de violência contra a mulher que acabam ocasionando vítimas fatais. Logo, ao utilizarmos essas variáveis, acredita-se delinear bem o tipo de convívio a vítima e o agressor possuíam no momento do fato criminoso.

\subsection{Método}

A ciência econômica através de seus métodos de pesquisas nos dá condições para pesquisar e concluir se houve ou não um real impacto na redução de homicídios femininos causados através da violência doméstica e familiar com base nas questóes de gênero.

Para realizar a pesquisa da análise da efetividade da Lei Maria da Penha, utilizase o método de diferenças em diferenças generalizados (Generalized difference-in-difference model - GDD), onde o grupo a ser tratado (homicídios praticados contra o sexo feminino) é confrontado com o grupo de controle (homicídios praticados contra o sexo masculino), antes e depois da Lei. O objetivo principal deste artigo é observar se houve ou não uma redução nas mortes femininas após a publicaçáo da Lei no 11.340 do ano de 2006, considerando o aspecto social e de relacionamento do ambiente em que se encontrava o agressor e a vítima, controlando a presença de Delegacias de Mulheres na cidade, o tipo de relacionamento íntimo, o possível nível de periculosidade, através do controle do uso de entorpecentes, entre outras características específicas da localidade. A equação de diferenças em diferenças Generalizadas (GDD) para computar o efeito da Lei Maria da Penha é tal que: 


$$
Y_{i g t}=\alpha+\gamma F_{g}+\delta L_{t}+\beta F_{g} . L_{t}+X_{i t}^{\prime} \theta+\mu_{i}+\pi_{t}+\varepsilon_{i g t}
$$

onde, $Y_{i g t}$ é a quantidade de homicídios registrada no município $i$, tanto para o gênero masculino quanto feminino (subscrito g), durante o período de 2002 a 2009 (subscrito $t$ ). A variável $F_{g}$ é uma variável binária que indica o grupo tratado (gênero feminino), enquanto o $L_{t}$ é uma variável binária que indica um (1) a partir da publicação da LMP e zero caso contrário, e $\delta$ é seu respectivo coeficiente. O vetor de variáveis $X_{i t}$ contém os controles (Presença de Delegacia Especializada, Densidade. Renda, Casamentos, Separaçóes e Divórcios, Posse de entorpecentes), e seus respectivos coeficientes $\theta$ associados. A equaçáo também considera os efeitos fixos municipais, $\mu_{i}$, que capturam as características constantes da cidade; e os efeitos fixos de tempo, $\pi_{t}$, que capturam os efeitos agregados do ano específico. Por fim, $\varepsilon_{i g t}$ representa o termo de erro. Cabe destacar que o coeficiente $\beta$ determina o parâmetro de interesse, o efeito da Lei no 11.340/06 sobre homicídios femininos, isto é, ele captura o efeito das diferenças em diferenças generalizadas. Espera-se que haja um efeito negativo e significativo caso a LMP tenha afetado o número de homicídios femininos em comparação com os homicídios masculinos para cada município gaúcho e considerando os controles.

\section{Resultados e análises}

A tabela 2 apresenta os resultados para a equação mencionada no tópico anterior que foi utilizada para a realização dessa pesquisa de análise de efetividade da Lei Maria da Penha. Realizamos três modelos econométricos para verificar a robustez dos resultados. Primeiro realizamos o modelo sem controles e sem considerar tanto os efeitos fixos municipais quanto os efeitos fixos de tempo (Modelo 1). Já o Modelo 2 apresenta todos os controles propostos e adiciona os efeitos fixos municipais. Por fim, o Modelo 3 apresenta todos os controles e todos os efeitos fixos.

Tabela 2 - Resultados

\begin{tabular}{|c|c|c|c|}
\hline & Modelo 1 & Modelo 2 & Modelo 3 \\
\hline Trat $^{*} L e i$ & $\begin{array}{c}-\boldsymbol{0 , 4 5 3 7 ^ { * * * }} \\
(0,1234) \\
\end{array}$ & $\begin{array}{c}-\boldsymbol{0}, \mathbf{4 5 4 6} \\
(0,1098) \\
\end{array}$ & $\begin{array}{c}-\mathbf{0 , 4 5 4 6} \mathbf{6}^{* * *} \\
(0,1098)\end{array}$ \\
\hline Lei_06 & $\begin{array}{c}0,4653^{* * *} \\
(0,0872) \\
\end{array}$ & $\begin{array}{c}0,1559^{* * *} \\
(0,0780) \\
\end{array}$ & $\begin{array}{c}0,0563 \\
(0,1240) \\
\end{array}$ \\
\hline Delegacias & & $\begin{array}{c}-1,5415^{* *} \\
(0,6584) \\
\end{array}$ & $\begin{array}{c}-1,5063^{* *} \\
(0,6587) \\
\end{array}$ \\
\hline Densidade & & $\begin{array}{c}0,0078 \\
(0,0056)\end{array}$ & $\begin{array}{c}0,0084 \\
(0,0056)\end{array}$ \\
\hline Renda & & $\begin{array}{c}2,33 \mathrm{e}-06^{* * *} \\
(1,41 \mathrm{e}-07)\end{array}$ & $\begin{array}{c}2,34 \mathrm{e}-06^{* * *} \\
(1,41 \mathrm{e}-07)\end{array}$ \\
\hline Casamentos & & $\begin{array}{c}0,0125^{* * *} \\
(0,0017)\end{array}$ & $\begin{array}{c}0,0126^{* * *} \\
(0,0017)\end{array}$ \\
\hline
\end{tabular}




\begin{tabular}{l|c|c|c}
\hline & Modelo 1 & Modelo 2 & Modelo 3 \\
\hline Separdivor & & $\begin{array}{c}-0,0083^{* * *} \\
(0,0013)\end{array}$ & $\begin{array}{c}-0,0081^{* * *} \\
(0,0013)\end{array}$ \\
\hline Pentorpe & & $\begin{array}{c}-0,0568^{* * *} \\
(0,4408)\end{array}$ & $\begin{array}{c}-0,0571^{* * *} \\
(0,0025)\end{array}$ \\
\hline Constante & $1,9572^{* * *}$ & $-0,8641^{* *}$ & $0,9382^{* *}$ \\
\hline E.F. Tempo & $(0,0436)$ & $(0,4608)$ & $(0,4439)$ \\
\hline E.F. Município & Não & Não & Sim \\
\hline R2 (quadrado) & Sim & Sim & Sim \\
\hline Observaçóes & 0,0041 & 0,2141 & 0,2150 \\
\hline
\end{tabular}

Notas: ${ }^{*} \mathrm{p}<0.10,{ }^{* *} \mathrm{p}<0.05,{ }^{* * *} \mathrm{p}<0.01$. Todas as regressôes são robustas a heterocedasticidade.

Fonte: elaborado pelo autor com a utilização do software Stata.

A variável Trat*Lei apresenta o efeito da lei sobre o gênero feminino, ela demonstra um efeito negativo e significativo com $1 \%$ de nível de significância para todos os modelos propostos. Pode-se interpretar que a Lei no 11.340/06 apresentou efetividade na luta contra a violência letal contra a mulher, resultado que corrobora o trabalho de Cerqueira et al. (2015), para os municípios do Rio Grande do Sul.

Além disso, os resultados mostram que a existência de Delegacias especializadas para defesa das mulheres faz com que o número de homicídios femininos diminuísse sistematicamente, a um nível de confiança de 5\%, para os modelos 2 e 3 . Conclui-se que esta variável é um controle importante para o estudo da efetividade da LMP. Em relação à variável de controle densidade, conclui-se, através dos resultados, que ela não manifesta importância estatística para o nível da taxa de homicídios femininos nas cidades do Estado, do mesmo modo, a variável renda do município apresentou também efeito significativo.

Utiliza-se as variáveis de controle do número de casamentos e do número de separaçóes e divórcios. A ideia é capturar o efeito da estabilidade familiar da sociedade. Sendo assim, os resultados demonstraram que quanto maior a quantidade de casamentos, maior a quantidade de homicídios, enquanto que um maior número de separaçóes e divórcios leva uma diminuição do número de homicídios de mulheres. Esses resultados sugerem que políticas de facilitação da separação ou divórcio (de unióes matrimoniais desequilibradas, ou que apresentam problemas) reduziria a violência contra pessoas do sexo feminino. Segundo a literatura, muitas vezes as mulheres continuam em seus casamentos pela dificuldade de conseguir o divórcio, submetendo-se a alguns tipos de agressóes e humilhaçóes. $\mathrm{O}$ uso de entorpecentes também foi considerado porque é uma variável que captura características ligadas a criminalidade, e pode estar relacionado a estrutura social e familiar. Esta última é significativa a um nível de $1 \%$ de confiança.

Logo, ao fim da aplicação do método de Diferenças em Diferenças Generalizadas $(G D D)$, percebe-se que mesmo tendo dados mais gerais em relação às vítimas fatais da violência contra a mulher, uma vez que possui-se apenas dados de homicídios em geral 
de homens e mulheres, enquanto que Cerqueira et al. (2015) possuía dados segregados de casos de homicídios que ocorreram dentro das residências, nossa regressão apontou que houve efetividade da Lei Maria da Penha, reduzindo de forma significativa o número de homicídios.

\section{Consideraçóes Finais}

A Lei no 11.340, conhecida como Lei Maria da Penha, representa um símbolo muito importante na luta para a coibição e prevenção da violência doméstica e familiar contra a mulher posto que, através dessa lei, sancionada no ano de 2006, o Brasil passou a tratar de forma integral o problema da violência contra a mulher. Mesmo sendo uma política de extrema importância, visto que a violência doméstica é definida pela ONU como uma violação aos direitos humanos, a superação desse tipo de violência ainda é um dos grandes desafios, tanto do nosso país como do resto do mundo.

Procurando estabelecer assistência e proteção para mulheres que estão em situação de violência doméstica e familiar, a Lei Maria da Penha, assegura, nos seus primeiros artigos, as garantias e direitos fundamentais para qualquer ser humano, independendo da sua classe, raça, etnia, orientação sexual, renda, etc., proporcionando condiçóes para exercer o direito à vida, à segurança, à saúde, ao respeito, e também à convivência familiar. A LMP estabeleceu uma maior proteção às vítimas da violência e facilitando a denúncia de agressóes moral, psicológica e/ou física, o que acabou afetando o comportamento dos agressores, que agora possuem uma maior probabilidade de serem condenados. Entretanto, mesmo essa Lei trazendo uma grande contribuiçáo para a luta contra a violência contra o sexo feminino, ainda havia lacunas na literatura em relação à avaliação da efetividade da Lei no 11.340/06. Para preencher essa lacuna, este trabalho testa se a LMP foi efetiva no combate a violência contra a mulher, através do método de diferenças em diferenças generalizadas, para os municípios do Rio Grande do Sul no período do ano de 2002 a 2009. Conclui-se que, para o período e os dados utilizados, a Lei Maria da Penha gerou efeitos significativos. Ou seja, a Lei que nasceu para combater a violência contra a mulher teve impacto negativo e estatisticamente significativo sobre a violência contra a mulher no Estado do Rio Grande do Sul.

\section{Referências}

BRASIL. Constituição (1988). Constituição da República Federativa do Brasil de 1988. Brasília, 5 de outubro de 1988. Disponível em: http://www.planalto.gov.br/ccivil_03/ constituicao/constituicaocompilado.htm. Acesso em: 17 nov. 2015.

BRASIL. Decreto no 1.973 , de $1^{\circ}$ de agosto de 1996. Promulga a Convenção Interamericana para Prevenir, Punir e Erradicar a Violência contra a Mulher, concluída em Belém do Pará, em 9 de junho de 1994. Brasília, 1o de agosto de 1996. Disponível em: http://www.planalto.gov.br/ccivil_03/decreto/1996/D1973.htm. Acesso em: 17 nov. 2015. 
BRASIL. Decreto-lei no 2.848, de 07 de dezembro de 1940. Código Penal. Rio de Janeiro, 07 de dezembro de 1940. Disponível em: http://www.planalto.gov.br/ccivil_03/ decreto-lei/Del2848.htm. Acesso em: 17 nov. 2015.

BRASIL. Lei no 11.340, de 07 de agosto de 2006. Cria mecanismos para coibir a violência doméstica e familiar contra a mulher, nos termos do $\$ 8^{\circ}$ do art. 226 da Constituição Federal, da Convenção sobre a Eliminação de Todas as Formas de Discriminação contra as Mulheres e da Convenção Interamericana para Prevenir, Punir e Erradicar a Violência contra a Mulher; dispóe sobre a criação dos Juizados de Violência Doméstica e Familiar contra a Mulher; altera o Código de Processo Penal, o Código Penal e a Lei de Execução Penal; e dá outras providências. Brasília, 07 de agosto de 2006. Disponível em: http:// www.planalto.gov.br/ccivil_03/_ato2004-2006/2006/lei/111340.htm. Acesso em: 17 nov. 2015.

BRASIL. Lei $\mathrm{n}^{\circ} 13.104$, de 09 de março de 2015. Altera o art. 121 do Decreto-Lei ${ }^{\circ}$ 2.848, de 07 de dezembro de 1940 - Código Penal, para prever o feminicídio como circunstância qualificadora do crime de homicídio, e o art. $1^{\circ}$ da Lei no 8.072 , de 25 de julho de 1990, para incluir o feminicídio no rol dos crimes hediondos. Brasília, 09 de março de 2015. Disponível em: http://www.planalto.gov.br/ccivil_03/_Ato20152018/2015/Lei/L13104.htm. Acesso em: 17 nov. 2015.

BRASIL. Lei no 9.099, de 26 de setembro de 1995. Dispóe sobre os Juizados Especiais Cíveis e Criminais e dá outras providências. Brasília, 26 de setembro de 1995. Disponível em: http://www.planalto.gov.br/ccivil_03/leis/L9099.htm. Acesso em: 17 nov. 2015.

CERQUEIRA, D. et al. Avaliando a efetividade da Lei Maria da Penha, [Online]. Instituto de Pesquisa Econômica Aplicada. Disponível em: http://www.ipea.gov.br/portal/ images/stories/PDFs/TDs/td_2048k.pdf. Acesso em: 17 nov. 2015.

CERQUEIRA, D.; LOBÃO, W. Determinantes da criminalidade: uma resenha dos modelos teóricos e resultados empíricos, [Online]. Instituto de Pesquisa Econômica Aplicada. Disponível em: http://www.ipea.gov.br/portal/images/stories/PDFs/TDs/ td_0956.pdf. Acesso em: 17 nov. 2015

COOTER, R.; ULLEN, T. Direito \& economia. 5. ed. Porto Alegre: Editora Bookman, 2010.

DIAS, M. B.; REINHEIMER, T. L. Violência doméstica e as unióes homoafetivas, [Online]. Compromisso e atitude Lei Maria da Penha. Disponível em: http://www. compromissoeatitude.org.br/violencia-domestica-e-as-unioes-homoafetivas-por-mariaberenice-dias-e-thiele-lopes-reinheimer. Acesso em: 7 jul. 2017.

FURTADO, I.; SILVA FILHO, G. Lei antifumo no Brasil: impactos no banimento do fumo em ambientes coletivos sobre a ocorrência de internaçóes hospitalares, [Online]. 42 Encontro Nacional de Economia. Disponível em: https://www.anpec.org. 
br/encontro/2014/submissao/files_I/i12-a7580ce65c0d79ad3418d80a1c5513d0.pdf. Acesso em: 17 nov. 2015.

GADONI-COSTA, L. M.; ZUCATTI, A. P. N.; DELL'AGLIO, D. D. Violência contra a mulher: levantamento dos casos atendidos no setor de psicologia de uma delegacia para a mulher. Estudos de psicologia, Campinas/SP, vol.28 n.2, pp.219-227, abr-jun, 2011.

GARCIA, L. et. al. Violência contra a mulher: feminicídios no Brasil, [Online]. Instituto de Pesquisa Econômica Aplicada. Disponível em: https://www.mpma. mp.br/arquivos/CAOPDH/IPEA_-_Viol\%C3\%AAncia_contra_a_mulher_-feminic\%C3\%ADdios_no_Brasil.pdf. Acesso em: 17 nov. 2015.

GARCIA, L.; FREITAS, L.; HÖFELMAN, D. Avaliação do impacto da Lei Maria da Penha sobre a mortalidade de mulheres por agressóes no Brasil, 2001 - 2011. Epidemiol. Serv. Saúde, Brasília/DF, vol.22, n.3, pp. 383-394, jul-set, 2013.

LIMA, R. B. Legislaçáo Criminal Especial Comentada. 2. ed. rev. ampl. e atual. Salvador: JusPodivm, 2014.

MANUEL, M.; BARROS, P.; CEREJO, S. Custos sociais e econômicos da violência exercida contra as mulheres em Portugal: dinâmicas e processos socioculturais. In: VI CONGRESSO PORTUGUÊS DE SOCIOLOGIA, 25 a 28 de junho de 2008, Universidade Nova de Lisboa.

MARTINS, A. P.; CERQUEIRA, D.; MATOS, M. A institucionalizaçáo das políticas públicas de enfrentamento à violência contra as mulheres no Brasil, [Online]. Instituto de Pesquisa Econômica Aplicada. Disponível em: https://www12.senado.leg.br/ institucional/omv/entenda-a-violencia/pdfs/a-institucionalizacao-das-politicas-publicasde-enfrentamento-a-violencia-contra-as-mulheres-no-brasil. Acesso em: 17 nov. 2015.

NUCCI, G. S. Leis penais e processuais penas comentadas. $5^{\circ}$ ed. São Paulo: Editora Revista dos Tribunais, 2010.

SCHRAIBER, L. et al. Violência contra a mulher: estudo em uma unidade de atenção primária à saúde. Revista de Saúde Pública. São Paulo, v.36, n.4, pp. 470-477, ago, 2002.

SHIMADA, E.; KANNEBLEY JR., S.; NEGRI, F. Efetividade da Lei do Bem no estímulo ao investimento em P\&D: uma análise com dados em painel, [Online]. 41 Encontro Nacional de Economia. Disponível em: https://www.anpec.org.br/ encontro/2013/files_I/i9-10d0885d8e8543656887a8a4cb6c4466.pdf. Acesso em: 17 nov. 2015.

SILVA, A.C. et. al. Violência contra a mulher: uma realidade imprópria. Rev. Ciênc. Saúde. Nova Esperança, v. 11, no 2, pp. 101-115, set, 2013. 
UCHÔA, C.F.; MENEZES, T. Spillover especial da criminalidade: uma aplicaçáo de painel espacial, para os estados brasileiros, [Online]. $40^{\circ}$ Encontro Nacional de Economia. Disponível em: https://www.anpec.org.br/encontro/2012/inscricao/files_I/i9fa2b8ebb634f17963afe1f307ae436f3.pdf. Acesso em: 17 nov. 2015.

VIAPIANA, L. T. Economia do crime: uma explicação para a formaçâo do criminoso. Porto Alegre: Age Editora, 2006.

WAISELFISZ, J. Mapa da Violência 2012 Atualizaçáo: homicídio de mulheres no Brasil. Centro Brasileiro de Estudos Latino-Americano. Disponível em: http://www. mapadaviolencia.org.br/pdf2012/MapaViolencia2012_atual_mulheres.pdf. Acesso em: 17 nov. 2015. 